\title{
Efeito do tamanho de partícula sobre a degradação ruminal do feno do restolho da cultura do girassol*
}

\author{
Effect of the particle size on ruminal degradation of \\ sunflower crop stubble hay
}

\author{
Bruno Spíndola Garcez, ${ }^{* *}$ Arnaud Azevêdo Alves, ${ }^{* *}$ Delano de Souza Oliveira, ${ }^{* *}$ Yanêz André Gomes Santana, ${ }^{* *}$ \\ Miguel Arcanjo Moreira Filho, ${ }^{* *}$ Juannira de Araújo Moura Reis ${ }^{\star * * *}$
}

\begin{abstract}
Resumo
Objetivou-se avaliar os teores de matéria seca, proteina bruta e fibra em detergente neutro e a degradabilidade da matéria seca (MS), proteína bruta (PB) e fibra em detergente neutro (FDN) do feno do restolho da cultura do girassol in situ em diferentes tamanhos de partículas (2 e $5 \mathrm{~cm}$ ), utilizando-se um bovino canulado, com amostras em sacos de náilon, incubadas nos tempos 6,24 e $72 \mathrm{~h}$. O feno de restolho da cultura do girassol triturado em partículas de $2 \mathrm{~mm}$ resultou em maior degradação por microrganismos da flora ruminal em relação à trituração a $5 \mathrm{~mm}$. Verificou-se que as partículas de maior tamanho apresentaram valores equivalentes para degradação da MS e FDN as 24 e 72 horas. Os parâmetros da degradação da FDN do feno do restolho da cultura do girassol indicam ser um volumoso com grande potencial para utilização na dieta de ruminantes. O feno do restolho da cultura do girassol, enquanto considerado um alimento volumoso, apresenta degradabilidade in situ da MS e FDN compatível com esta classe de alimentos, podendo ser considerado uma boa fonte de inclusão em dietas para ruminantes. Também se deve considerar o elevado teor de PB associado à degradação ruminal deste constituinte, favorecendo à atividade fermentativa pela população microbiana do ambiente ruminal.
\end{abstract}

Palavras-chave: degradação in situ, fibra em detergente neutro, Helianthus annuus.

\begin{abstract}
It was aimed to evaluate the degradability of dry matter (DM), crude protein (CP) and neutral detergent fiber (NDF) of the stubble sunflower crop hay in situ in different particle sizes, using a cannulated bovine, with samples in nylon bags incubated in the 6,24 and $72 \mathrm{~h}$. The stubble sunflower crop hay grinded in $2 \mathrm{~mm}$ particles sized resulted in greater degradation by the rumen microorganisms compared to samples grinded in $5 \mathrm{~mm}$. It was found that the larger particles had equivalent values for DM and NDF degradation at 24 and 72 hours. The parameters of NDF degradation of the stubble sunflower crop hay to indicate be a roughage with great potential for use in the ruminant diet. The stubble sunflower crop hay, while considered a roughage food, presents in situ DM and NDF compatible with this kind of food, and it can be considered a good source of inclusion in diets for ruminants. Also to consider the higher protein value associated with ruminal degradation of this constituent, favoring the fermentation activity by the microbial population in the rumen.
\end{abstract}

Keywords: Helianthus annuus, in situ degradation, neutral detergent fiber.

\section{Introdução}

A alimentação animal está relacionada com o estado nutricional do animal, e depende de quatro fatores indispensáveis aos sistemas de formulação de dietas: exigências nutricionais, quantidade de nutrientes ingeridos pelo animal, composição química e degradabilidade e/ou digestibilidade da matéria seca e dos nutrientes. Segundo Macedo Júnior et al. (2007), a avaliação desses parâmetros faz-se imprescindível, por apresentarem alta correlação com o consumo de massa seca, bem como com a eficácia da absorção e aproveitamento dos nutrientes.

O girassol (Helianthus annuus) é caracterizado por apresentar resistência ao frio e ao calor, quando comparado às demais culturas, além de ampla adaptabilidade às diferentes condições edafoclimáticas, sendo capaz de tolerar períodos secos e produzir grande quantidade de matéria seca. $O$ uso dessa forrageira na alimentação animal sob a forma de feno surge como boa alternativa para regiões que apresentam períodos de déficit hídrico, e que impossibilitam a produção de alimentos volumosos de boa qualidade e, consequentemente, a manutenção da produção animal ao longo do ano (Nunes et al., 2007).

O restolho da cultura do girassol corresponde à parte aérea da planta sem os capítulos, colhidos após a maturação natural a campo. No entanto, para que haja melhor aproveitamento das palhadas pelos ruminantes, é necessário identificar os melhores meios de utilização dos nutrientes, principalmente para animais

\footnotetext{
${ }^{*}$ Recebido em 07 de janeiro de 2016 e aceito em 8 de abril de 2016.

**Programa de Pós Graduação em Ciência Animal/CCA/UFPI, Teresina-PI.

***Programa Nacional de Pós Doutorado, Universidade Federal do Maranhão, Campus Chapadinha, MA.

****Engenheira Agrônoma, UFPI, Teresina-PI.
} 
em estados fisiológicos de menor exigência nutricional ou em baixa produção.

A determinação dos parâmetros de degradabilidade de alimentos para ruminantes constitui um fator relevante na alimentação animal, diretamente relacionada ao desempenho do animal e indispensável em sistemas de formulação de dietas. A degradabilidade ruminal in situ tem por objetivo propiciar informações quanto às frações solúvel (a) e lentamente degradável $(b)$, à taxa de degradação da fração $b(c)$, à degradação potencial (DP) e à degradação efetiva (DE) para taxas de passagens 2; 5 e 8\%/h (CAMPOS et al., 2011).

Objetivou-se com esta pesquisa, avaliar o valor nutritivo do feno do restolho da cultura do girassol quanto à composição química e degradabilidade ruminal in situ da matéria seca, proteína bruta e fibra em detergente neutro.

\section{Material e métodos}

As amostras do feno do restolho da cultura do girassol foram obtidas no Centro de Ciências Agrárias da Universidade Federal do Piauí e submetidas ao processo de pré-secagem em estufa com circulação forçada de ar a $55 \pm 5^{\circ} \mathrm{C}$, por 72 horas e, em seguida, foram moídas em moinho tipo Willey com peneira de malha com crivos de diâmetro 2 e $5 \mathrm{~mm}$ e conservadas em sacos plásticos vedados, devidamente identificados.

As análises químicas e o ensaio de degradabilidade in situ foram realizados no Laboratório de Nutrição Animal do Departamento de Zootecnia/CCA/UFPI. Determinou-se o teor de matéria seca (MS) e proteína bruta (PB) segundo metodologias descritas por Silva e Queiroz (2002) e de fibra em detergente neutro (FDN) segundo Van Soest et al. (1991) descrito e modificado por Souza et al. (1999).

Para avaliação da degradabilidade in situ da MS, PB e FDN do feno do restolho da cultura do girassol utilizou-se um bovino canulado no rúmen, com $600 \mathrm{~kg}$ de peso vivo. Durante o período experimental, incluindo o período de adaptação de sete dias, forneceu-se dieta composta por $80 \%$ de volumoso (capim Brachiária) e $20 \%$ de concentrado (ração comercial), fornecida em duas refeições (as 8 e 16 h), além de mistura mineral completa e água à vontade.

Utilizou-se sacos de náilon medindo internamente $8 \times 12 \mathrm{~cm}$, com porosidade $50 \mu \mathrm{m}$, previamente secos em estufa de circulação forçada de ar a $55 \pm 5^{\circ} \mathrm{C}$ e posteriormente pesados. Adicionouse $3,0 \mathrm{~g}$ de amostra trituradas 2 ou $5 \mathrm{~mm}$, por saco, de acordo com metodologia adotada por Alves et al. (2007), com 5 sacos por amostra em cada tempo de incubação somados ao tempo 0 , totalizando 40 sacos, fechando-os com vedantes de náilon recobertos por ligas de látex, sendo novamente pesados, e incubou-se através da cânula ruminal, sendo estes suspensos por um fio guia. Utilizou-se um peso de $500 \mathrm{~g}$ para ancorar o conjunto no ambiente do saco ventral do rúmen (Ezequiel e Galati, 2007)

Adotaram-se os tempos de incubação 6, 24 e 72 h, segundo o NRC (2001). A incubação ocorreu em ordem decrescente de tempo, proporcionando-se retirada de todos os sacos simultaneamente do ambiente ruminal. Os sacos desincubados foram imersos em recipiente com água gelada para cessar o processo fermentativo, sendo em seguida lavados em máquina de lavar tipo tanquinho, até a água mostrar-se límpida e présecos em estufa de circulação forçada de ar a $55 \pm 5^{\circ} \mathrm{C}$, por 72 h, para subsequentes análises químicas, quanto aos teores de MS, PB e FDN.

A fração prontamente solúvel em água foi determinada imergindo-se os sacos contendo as amostras equivalentes às utilizadas na incubação, em banho-maria a $39^{\circ} \mathrm{C}$, por $1 \mathrm{~h}$, correspondendo esta fração à parte solúvel do alimento mais as partículas eliminadas através da porosidade dos sacos.

Os parâmetros de degradação in situ (a, b e c) e a degradabilidade potencial da MS, PB, foram estimados pelo modelo exponencial por Ørskov e Mcdonald (1979), expresso por: DP = A-B.e-c.t em que, $\mathrm{DP}=$ percentagem real do nutriente degradado após t horas de incubação no rúmen; $A$ = potencial máximo de degradação do material no saco de náilon; $B$ = fração potencialmente degradável do material que permanece no saco de náilon após o tempo zero; c = taxa de degradação da fração remanescente no saco de náilon após tempo zero; $\mathrm{t}=$ tempo de incubação.

A degradabilidade efetiva (DE) da MS e $\mathrm{PB}$ no rúmen foi estimada considerando-se a taxa de passagem 2, 5 e 8\%/h (AFRC, 1993), para cada tratamento utilizando-se a equação proposta por Ørskov e McDonald (1979): DE = a + [(b c)/(c + k)], em que, DE = Degradação efetiva; $a$ = fração solúvel, rapidamente degradada; $\mathrm{b}=$ fração insolúvel, lentamente degradada; $c$ = taxa fracional de degradação de $b ; k$ = taxa de passagem.

Para estimativa dos parâmetros de degradação da FDN adotouse modelo de Mertens e Loften (1980): Rt = B.e-ct + I, onde: Rt = fração degradada no tempo $\mathrm{t}$; I= fração indegradável. Após os ajustes da equação de degradação da FDN, precedeu-se a padronização das frações, conforme proposto por Waldo et al. (1972), utilizando-se as equações: $B P=B /(B+I) \times 100$ e IP $=$ $\mathrm{I} /(\mathrm{B}+\mathrm{I}) \times 100$, em que: $\mathrm{BP}=$ fração potencialmente degradável padronizada (\%) IP = fração indegradável padronizada (\%).

Adotou-se no experimento o delineamento inteiramente casualizado em parcela subdividida com tratamentos (tamanho de partícula) representando as parcelas e os tempos de incubação (6, 24 e 72 horas) as subparcelas. Para obtenção dos parâmetros de degradação, utilizou-se o procedimento para modelo não lineares (PROC NLIN) do SAS (Statistical Analysis System, versão 8).

\section{Resultados e discussão}

Os valores de composição química do feno do restolho da cultura do girassol estão apresentados na tabela 1. Mesmo considerado um restolho de cultura, a forragem apresentou valores semelhantes aos obtidos para volumosos, como os obtidos por Silva et al. (2014) para capim Andropogon com 70 dias de rebrote $(75,94 \%)$ e por Leonel et al. (2009) para capim Mombaça acima de 60 dias $(76,11 \%)$.

Os teores de PB ficaram acima do limite mínimo estipulado por Van Soest (1994) para adequada fermentação microbiana, no entanto, são necessários estudos mais detalhados quanto às frações nitrogenadas da PB do feno do restolho da cultura do girassol, visando quantificar a proteína disponível ao processo fermentativo ruminal e fração indisponível desse nutriente. 
Tabela 1: Teores de MS, PB e FDN do feno do restolho da cultura do girassol

Constituintes químicos

\begin{tabular}{lc}
\hline Matéria seca $^{1}$ & 78,85 \\
Proteína bruta $^{2}$ & 7,59 \\
Fibra em detergente neutro $^{2}$ & 79,45 \\
\hline
\end{tabular}

$1 \%$ da matéria natural

$2 \%$ da matéria seca

A trituração do feno de restolho da cultura do girassol a partículas de $2 \mathrm{~mm}$ resultou em maiores valores de degradação em relação ao tamanho de $5 \mathrm{~mm}$ (Tabela 2). O tamanho de partícula é fator preponderante para a atuação dos microrganismos ruminais sobre os componentes do alimento, principalmente a fração fibrosa (Owens e Goetsch, 1993), considerando-se que quanto menor o tamanho de partícula, maior a área de superfície específica para colonização pela microbiota ruminal, influenciando assim as estimativas da taxa de degradação da MS dos alimentos, principalmente a degradação dos componentes fibrosos.
Verificou-se elevada taxa de degradação c $(9,97 \% / h)$ da MS e embora os restolhos de culturas geralmente apresentem maior proporção de parede celular na MS, a fração potencialmente degradável (b) desse constituinte do feno do restolho da cultura do girassol $(36,32 \%)$ foi degradada a uma taxa acima dos obtidos para volumosos como capim-andropógon $(2,81 \%)$ (Silva et al., 2014), milheto (2,24\%) (Cavalcanti et al., 2012) e Capim Tanzânia (2,67\%) (Simili et al., 2014), indicando potencial forrageiro para o subproduto.

Tabela 3: Parâmetros da cinética de degradação ruminal da matéria seca (MS) e da proteína bruta (PB) do feno do restolho da cultura do girassol triturado a partículas de $2 \mathrm{~mm}$

\begin{tabular}{ccccc}
\hline Constituinte & \multicolumn{3}{c}{ Parâmetros $^{1}$} & $\mathrm{R}^{2}$ \\
\cline { 2 - 4 } & $\mathrm{a}(\%)$ & $\mathrm{b}(\%)$ & $\mathrm{c}(\% / \mathrm{h})$ & \\
\hline MS & 24,37 & 36,32 & 9,97 & 98,26 \\
PB & 31,27 & 49,76 & 11,80 & 98,30 \\
\hline
\end{tabular}

${ }^{1} a=$ fração solúvel em água; $b=$ fração potencialmente degradável; $c=$ taxa de degradação da fração $b$.
Tabela 2: Degradação dos constituintes do feno do restolho da cultura do girassol em dois tamanhos de partículas, em função dos períodos de incubação (horas)

\begin{tabular}{|c|c|c|c|c|c|c|}
\hline \multirow[b]{2}{*}{ Nutriente } & \multirow{2}{*}{$\begin{array}{l}\text { Tamanho da } \\
\text { Partícula } \\
\text { (mm) }\end{array}$} & \multicolumn{3}{|c|}{ Tempo de incubação (h) } & \multirow[b]{2}{*}{ EPM } & \multirow[b]{2}{*}{$P$} \\
\hline & & 6 & 24 & 72 & & \\
\hline \multirow[t]{2}{*}{ Matéria seca } & 2 & 0,3774 & 0,5688 & 0,6066 & 0,07 & 0,021 \\
\hline & 5 & 0,2829 & 0,5659 & 0,5607 & 0,07 & 0,041 \\
\hline \multirow[t]{2}{*}{ Proteína bruta } & 2 & 0,4277 & 0,7646 & 0,8102 & 0,09 & 0,032 \\
\hline & 5 & 0,1802 & 0,5574 & 0,7522 & 0,08 & 0,012 \\
\hline \multirow[t]{2}{*}{ Fibra em detergente neutro } & 2 & 0,3807 & 0,5195 & 0,5405 & 0,07 & 0,022 \\
\hline & 5 & 0,2329 & 0,4875 & 0,4748 & 0,06 & 0,036 \\
\hline
\end{tabular}

A maior proporção da MS do feno do restolho da cultura do girassol é composta por parede celular, representada do ponto de vista nutricional pela FDN (Tabela 1), o que pode ter contribuído para a aproximação dos valores para degradação da MS e da FDN pelos microrganismos do rúmen nos três tempos de incubação (Tabela 2). Verificou-se que as partículas de maior tamanho $(5 \mathrm{~mm})$ apresentaram valores equivalentes para degradação da MS e FDN às 24 e 72 horas, e sempre menores que os observados para o feno incubado com partículas de menor tamanho $(2 \mathrm{~mm})$. Assim, a adoção dos modelos para estimativa dos parâmetros de degradação da MS, PB e FDN, só foram adequados quando realizada a incubação de partículas trituradas a $2 \mathrm{~mm}$.

A fração solúvel da MS e PB do feno do restolho da cultura do girassol apresentou-se elevada, $24,37 \%$ e $31,27 \%$, respectivamente e podem estar associados a perdas decorrentes do processo de lavagem ou mesmo de constituintes solúveis deste restolho de cultura (Tabela 3). Os valores da fração da MS e PB do feno mostram-se semelhantes aos obtidos para o capim-elefante aos 60 dias de idade por Martins-Costa et al. (2008), 22,67 e 32,17\%, respectivamente.
Os parâmetros de degradação da fração FDN encontram-se na tabela 4. Os valores da fração potencialmente degradável (Bp) e indigestível (Ip) de feno do restolho da cultura do girassol (Tabela 4) foram elevados e superiores a volumosos de média qualidade avaliados por Muniz et al. (2012) obtendo valores de $31 \%$ para feno e mata-pasto (Senna obtusifolia L.), e 28,91\% para mororó (Bauhinia cheilanta). Os parâmetros da degradação da FDN do feno do restolho da cultura do girassol, com fração potencialmente degradável $\left(B_{p}\right)$ de $54,06 \%$ e taxa de degradação da fração $B_{p}$ de $11,3 \% / h$, indicam ser um volumoso com grande potencial para utilização na dieta de ruminantes, mesmo com valores elevados de componentes indegradáveis. O coeficiente

Tabela 4: Parâmetros da cinética de degradação ruminal da fibra em detergente neutro (FDN) do feno do restolho da cultura do girassol triturado a partículas de $2 \mathrm{~mm}$, a partir da equação não linear $R_{t}=B^{*} e^{-c t}+1$

\begin{tabular}{lccccc}
\hline \multirow{2}{*}{ Constituinte } & \multicolumn{4}{c}{ Parâmetros $^{1}$} & \multirow{2}{*}{$\mathrm{R}^{2}$} \\
\cline { 2 - 5 } & $\operatorname{Lag}(\mathrm{h})$ & $\mathrm{B}_{\mathrm{p}}(\%)$ & $\mathrm{l}_{\mathrm{p}}(\%)$ & $\mathrm{k}\left(\% \mathrm{~h}^{-1}\right)$ & \\
\hline $\begin{array}{l}\text { Fibra em detergente } \\
\text { neutro }\end{array}$ & 5,2 & 54,06 & 45,94 & 11,3 & 96,02 \\
\hline
\end{tabular}

${ }^{1} \mathrm{Lag}=$ Tempo de colonização; $\mathrm{B} / \mathrm{B}=$ fração insolúvel potencialmente degradável ajustada; $I_{p}=$ fração indegradável ajustada; $k$ = taxa de degradação da fração $B_{p} ; R^{2}=$ coeficiente de determinação.

de determinação $\left(R^{2}\right)$ foi elevado em todos os parâmetros avaliados, o que demonstra adequado ajuste do modelo as variáveis analisadas.

A fração indegradável $(45,94 \%)$ da FDN contribui sensivelmente para a repleção ruminal, além de não ser disponível como fonte 
de energia para o crescimento microbiano. Dessa forma, animais alimentados com o feno do restolho da cultura do girassol em altas proporções, podem sofrer efeito desse mecanismo fisiológico e resulte em limitação do consumo pelos animais (Vieira et al., 1997).

Quanto ao tempo de colonização (lag) o valor obtido foi elevado e superiores aos encontrados para gramíneas $(4,6 \%$ ) (Jobim et al., 2011) refletindo na capacidade de aderência dos microrganismos ruminais as partículas de fibra e tende a ser mais elevado quanto menor valor nutritivo da forrageira, no entanto, observa-se nessa pesquisa altas taxas de degradação da MS e PB (Tabela 3), o que não promoveu redução na capacidade fermentativa dos micro-organismos ruminais.

A degradação potencial (DP) e a degradação efetiva (DE) da MS, PB e FDN do feno do restolho da cultura do girassol foram elevadas (Tabela 5), com degradação potencial da PB $(81,01 \%)$ superior aos obtidos para feno de capim Tifton com 23 dias de idade de pós rebrota por Jobim et al. (2011) $(74,12 \%)$ e Ferreira

\section{Conclusões}

O feno do restolho da cultura do girassol, enquanto considerado um alimento volumoso, apresenta degradabilidade in situ da MS e FDN compatível com esta classe de alimentos, podendo ser

\section{Referências}

AGRICULTURAL AND FOOD RESEARCH COUNCIL - AFRC. Energy and protein requirements of ruminants. Wallingford, UK: CAB International, 1993. $159 \mathrm{p}$.

ALVES, A.A.; SALES, R.O.; NEIVA, J.N.M.; MEDEIROS, A.N.; BRAGA, A.P.; AZEVEDO, A.R. Degradabilidade ruminal in situ de vagens de faveira (Parkia platycephala Benth.) em diferentes tamanhos de partículas. Arquivo Brasileiro de Medicina Veterinária e Zootecnia, v. 59, n. 4, p. 1045-1051, 2007.

CAMPOS, M.M.; BORGES, A.L.C.C.; LOPES, F.C.F. PANCOTI, C.G.; REIS E SILVA, R. Degradabilidade in situ da cana-deaçúcar tratada ou não com óxido de cálcio, em novilhas leiteiras Holandês x Gir. Arquivo Brasileiro de Medicina Veterinária e Zootecnia, v. 63, n. 6, p. 1487-1492, 2011.

CAVALCANTI, D.R.; PERIN, F.B.; BENEDETTI, E. Degradabilidade in situ da matéria seca de três forrageiras tropicais nas formas in natura e ensilada. Arquivo Brasileiro de Medicina Veterinária e Zootecnia, v. 64, n.1, p. 163-168, 2012.

EZEQUIEL, J.M.B.; GALATI, R.L. Técnicas in vitro e in situ para estimativa da degradabilidade ruminal de alimentos. In: SIMPÓSIO INTERNACIONAL AVANÇOS EM TÉCNICAS DE PESQUISA EM NUTRIÇÃO DE RUMINANTES, Pirassununga, 2007. Anais... Pirassununga: USP, 2007. CD-ROM.

FERREIRA, G.D.G.; SANTOS, G.T.; CECATO, U.; CARDOSO, E.C. Composição química e cinética da degradação ruminal de gramíneas do gênero Cynodon em diferentes idades ao corte. Acta Scientiarum Animal Science, v. 27, n. 2, p. 189-197, 2005. JOBIM, C.C., FERREIRA, G.A.; BUMBIERIS JUNIOR, V.H.; JUNIOR, M.C. SANTOS, G.T. Cinética de degradação ruminal dos fenos de alfafa e Tifton-85 e da silagem de milho. Semina: Ciências Agrárias, v. 32, n. 2, p.747-758, 2011. et al. (2005) para cultivares de gramíneas de gênero Cynodon manejadas com $21(67,8 \%)$ e 44 dias $(72,7 \%)$.

Tabela 5: Degradabilidade potencial (DP) e efetiva (DE) da matéria seca (MS), da proteína bruta (PB) e da fibra em detergente neutro (FDN) do feno do restolho da cultura do girassol triturado a partículas de $2 \mathrm{~mm}$, calculada para taxa de passagem de $2 \%$ por hora

\begin{tabular}{lcc}
\hline Constituinte & DP (\%) & DE (\%) \\
\hline Matéria seca & 60,66 & 54,62 \\
Proteína bruta & 81,01 & 73,82 \\
Fibra em detergente neutro & 54,06 & 45,93 \\
\hline
\end{tabular}

A degradação potencial da proteína influencia o aproveitamento ruminal dos demais componentes nutricionais, onde melhor degradação aumenta a quantidade de $\mathrm{N}$ disponível para o metabolismo, melhorando o aproveitamento das demais frações do alimento, como a fibra em detergente neutro $(54,06 \%)$.

indicado para inclusão em dietas para ruminantes. Também se deve considerar o bom valor proteico, associado à degradação ruminal deste constituinte, favorecendo a atividade fermentativa pela população microbiana do ambiente ruminal.

MACEDO JUNIOR, G.L.; ZANINE, A.M.; BORGES, I.; PÉREZ, J.R.O. Qualidade da Fibra para a dieta de ruminantes. Ciência Animal, Fortaleza, v. 17, n. 1, p. 7-17, 2007.

MARTINS-COSTA, R.H.A.; CABRAL, L.S.; BHERING, M.; ABREU, J.G.; ZERVOUDAKIS, J.T.; RODRIGUES, R.C.; OLIVEIRA, I.S. Valor nutritivo do capim-elefante obtido em diferentes idades de corte. Revista Brasileira de Saúde e Produção Animal, v. 9, n. 3, p. 397-406, 2008.

MERTENS, D.R.; LOFTEN, J.R. The effect of starch on forage fiber digestion kinetics in vitro. Journal of Dairy Science., v. 63, p. 1437-1446, 1980.

MUNIZ, E.B.; MIZUBUITI, I, Y.; PEREIRA, E.S.; PIMENTEL, P.G.; RIBEIRO, E.L.A.; PINTO, A.P. Cinética ruminal da fração fibrosa de volumosos para ruminantes. Revista Ciência Agronômica, v. 43, n. 3, p. 604-610, 2012.

NATIONAL RESEARCH COUNCIL. NRC. Nutrient requirements of dairy cattle. $7^{\text {th }}$ rev. ed. Washington, D.C.: National Academy Press, 2001. $381 \mathrm{p}$.

NUNES, H.; ZANINE, A.M.; MACHADO, T.M.M.; CARVALHO, F.C. Alimentos alternativos na dieta dos ovinos: Uma revisão. Archivos Latinoamericanos de Producción Animal, v. 5, n. 4, p. 147-158, 2007.

ØRSKOV, E.R.; McDONALD, I. The estimation of protein degradability in the rumen from incubation measurements weighted according to rate of passage. Journal of Agricultural Science, v. 92, p. 499-503, 1979.

OWENS, F.N.; GOETSCH, A.L. Ruminal Fermentation. In: $\mathrm{CHURCH}$, D. C. (Ed.). The Ruminant Animal: digestive physiology and nutrition. 5. ed. New Jersey: Englewood, Cliffs, 1993. p.145171.

SILVA, D.J.; QUEIROZ, A.C. Análise de alimentos: métodos químicos e biológicos. 3. ed., Viçosa: UFV, 2002. 235 p. 
SILVA, D.C.; ALVES, A.A.; LACERDA, M.S.B.; MOREIRA FILHO, M.A.; OLIVEIRA, M.E.; LAFAYETTE, E.A. Valor nutritivo do capim-andropogon em quatro idades de rebrota em período chuvoso. Revista Brasileira de Saúde e Produção Animal, v.15, n. 3, p. 626-636 jul./set., 2014.

SIMILI, F.F.; LIMA, M.L.P.; MEDEIROS, M.I.M.; PAZ, C.C.P.; REIS, R.A. Degradabilidade in situ do híbrido de sorgo e do capim-Tanzânia em vacas suplementadas no outono. Boletim de Indústria Animal, v.71, n. 2, p. 127-134, 2014.

VAN SOEST, P.J. Nutritional ecology of the ruminant. Ithaca, New York: Cornell University Press, 1994. 476 p.
VAN SOEST, P.J.; ROBERTSON, J.B.; LEWIS, B.A. Methods for dietary fiber, neutral detergent fiber, and nonstarch polysaccharides in relation to animal nutrition. Journal of Dairy Science, v.74, n.10, p.3583-3597, 1991.

VIEIRA, R. A. M.; PEREIRA, J. C.; MALAFAIA, P. A. M.; QUEIROZ, A. C. The influence of the elephant-grass (Pennisetum purpureum Schum., Mineiro Variety) growth on nutrient kinetics in the rumen. Animal Feed Science and Technology, n. 67, p.151-161, 1997.

WALDO, D.R.; SMITH, L.W.; COX, L.E. Model of cellulose disappearance from the rumen. Journal of Dairy Science, v. 55, p. 125-129, 1972. 